\section{The Intraoperative Hemodynamic Control through Functional Parameters in Free Flap Reconstruction in Head and Neck Surgery: Our Initial Expertise}

Rosella Bulgheroni1, Alessandro Bacuzzi'1, Luca Guzzetti", Mauro Del Romano', Dunia D'Onofrio', Gaia Rossini', Andrea Del Bosco', Massimiliano Bianchi'1, Raffaele Novario', Marco Giudice $^{2}$, Mario Cherubino ${ }^{3}$, Giovanni Cantone ${ }^{3}$ and Salvatore Cuffari ${ }^{1}$

${ }^{1}$ Anesthesia Department, University Hospital Varese, Italy

${ }^{2}$ Department of Surgical Sciences, University Hospital Varese, Italy

${ }^{3}$ Plastic and Reconstructive Surgery Department, University Hospital Varese, Italy

\begin{abstract}
Background: The role of intravenous fluids during surgical procedures is debated. Actually, many studies show the utility of managing hemodynamic control in operating room through non-invasive or minimally invasive cardiac output monitoring. The intraoperative fluids administration could be guided by functional hemodynamic parameters to avoid hypervolemia during free flaps reconstruction in ENT surgery.

Materials and Method: In our ENT department we have used both functional hemodynamic parameters through VIGILEO ${ }^{\circledR}$ monitoring (VIGILEO group) and anaesthesiological recommendations (STANDARD group) during major ENT surgical procedures with free flap reconstruction. We describe our data in terms of intraoperative hemodynamics management and rate of complications in both groups.

Results: We have done a retrospective examination about 17 patient's undergone surgical procedures in head and neck departments with free flaps reconstruction from November 2012 to February 2014. We had only one major complication (venous
\end{abstract}

*Corresponding author: Luca Guzzetti, Anesthesia Department, University Hospital Varese, Italy, Tel: ; E-mail: luca.guzzetti@hotmail.it

Citation: Bulgheroni R, Bacuzzi A, Guzzetti L, Romano MD, D'Onofrio D, et al., (2014) The Intraoperative Hemodynamic Control through Functional Parameters in Free Flap Reconstruction in Head and Neck Surgery: our Initial Expertise. J Anesth Clin Care 1: 004.

Received: October 01, 2014; Accepted: November 27, 2014; Published: December 11, 2014 anastomosis failure) in the VIGILEO group. We've found that there are no statistical differences in amount of volume fluids infused (VIGILEO 477, $7 \mathrm{ml} / \mathrm{h}$ STANDARD group 490, $2 \mathrm{ml} / \mathrm{h}$ ) between study groups. We have found a systematically use of vasoactive drugs in continuous infusion only in VIGILEO group.

Discussion: Hemodynamic optimization has been related to a better outcome in surgical procedures with an improvement in microcirculation anastomosis. The role of functional hemodynamics parameters in ENT surgery with free flaps reconstruction is promising. Further assessments in large randomized trial are necessary.

Keywords: Free flaps; Functional hemodynamic parameters; Major head and neck surgery; VIGILEO ${ }^{\circledR}$

\section{Introduction}

The free flaps transfer is a surgical procedure with many risks related to hypoperfusion of free vascularized tissues transferred. Tumor excision is a lengthy and complex surgical procedure and an inadequate fluids administration is related to a worsen outcome [1]. It's important to remind that the blood circulation is regulated by the Poiseulle-Hagen equation,

\section{Blood Flow $=\Delta \mathrm{P} \pi \mathrm{r} 4 / 8 \eta \mathrm{l}$}

Where $\Delta \mathrm{P}=$ pressure difference between two ends, $\mathrm{r}=$ radius, $\eta=$ viscosity and $l=$ length.

The hemodynamic response to a sudden change in blood flow influences the vessel cross-sectional area, resulting in an expected free flap suffering. Reasons of this association are multiple but it is well described that the intraoperative fluids administration changes the vascular barrier, modifying the endothelial surface layer [2]. The intraoperative fluid management has to replace losses occurring in preoperative period [3] and losses occurring during surgical time (urine production, insensible perspiration, blood losses) and now it is still debated the fluid benefit intake between crystalloid and colloid $[4,5]$. The optimal strategy in terms of fluid type (colloids vs. crystalloids) and volume (restrictive or liberal) remains controversial and uncertain. Actually a better fluids management seems to be fluid administration guided by hemodynamic goals $[2,6,7]$. For these reasons a tailored anesthesia management in patients with significant comorbidities [8,9] (elderly, smokers, alcohol abusers, malnourished) seems to be an optimal choice. The anesthetic challenges in the resection and reconstructive ENT surgery are many and related largely to patient's comorbidities [10], airway control [11], procedures length and, essentially, to the maintenance of an adequate perfusion in free flaps [12]. Therefore, the primary objective of this retrospective analysis is to compare our functional hemodynamic parameters targets, through FloTrac $^{\mathrm{Tw}} /$ Vigileo $^{\mathrm{mm}}$ monitoring, to standard anaesthesiological recommendations based on diuresis, estimated perspiration, blood pressure and lactate values. FloTrac $^{\mathrm{Tm}} /$ Vigileo $^{\mathrm{ma}}$ implementation is increasing in all operating rooms as a minimally invasive hemodynamic monitoring; through an invasive radial or femoral artery line, this system derives functional hemodynamic data as Cardiac Output (CO), Cardiac Index (CI), Systemic Vascular Resistance (SVR), Stroke Volume (SV), Stroke 
Volume Index (SVI), and Stroke Volume Variation (SVV) avoiding the risks of insertion of a central venous line, with particular attention to PAC. The essential conditions to have valid information from this monitoring, as recommended by service provider, are: regular heartbeat (sinusal rhythm), mechanical ventilation with closed chest and a tidal volume with at least $7 \mathrm{~mL} / \mathrm{kg}$ and an adequate myoresolution.

\section{Material and Methods}

We have done a review of all patients with head and neck cancer undergoing free tissue transfer at University Hospital of Varese (Italy) from November 2012 to February 2014. We have analyzed all medical charts including demographic data, laboratory values, comorbidity and surgical time. In particular, we have extracted all intraoperative anaesthesiological data finding differences in terms of hemodynamic treatments between a group of patients treated with FloTrac ${ }^{\mathrm{m}} / \mathrm{Vigileo}^{\mathrm{tm}}$ monitoring (VIGILEO group) and another one treated with hemodynamic targets (STANDARD group) as pressure values, urine output and lactate values. In our center there is full cooperation between the Department of Otolaryngology and that of Plastic Surgery, in which these free tissue transfers are performed by two surgeons routinely.

We admitted a small population of 17 patients (divided into 10 cases for VIGILEO $^{\circ}$ group and 7 for STANDARD group). Age ranges for both VIGILEO and STANDARD groups between 37 and 81 years old, with a mean age of 61.4 and 67.5 years old respectively. ASA score, BMI values and comorbidities are reported in table 1 to describe our population.

All these ENT surgical procedures were performed during general anesthesia with propofol and remifentanil infusion to achieve a BIS value minor to 60 . The primary outcome of this retrospective analysis is the complications rate defined as re-operation or adverse events that prolongs the length of hospital stay in both groups. As secondary outcome, we have analyzed intraoperative treatment of hemodynamics variables, in both groups, focusing our attention on fluids balance.

\section{Statistical Analysis}

Statistical analysis was done using MedCalc ${ }^{\circledR}$ software version 12.2.1.0. Nonparametric data were analyzed using the Mann-Whitney. Proportions comparison was performed through Fischer's exact text because the frequencies were very low. Statistical significance was defined as a $\mathrm{P}$ value $\leq .05$.

\section{Results}

We have analyzed 17 patients (VIGILEO GROUP 10 patients; STANDARD GROUP: 7 patients) undergone to free flaps reconstruction in head and neck department from November 2012 to February 2014. No differences between groups were observed in demographical data, patient's characteristics, surgical procedures time (Table 1).

No significant differences were observed about adverse events (re-operation, intra-hospital death) and in Length of Stay (LOS) in both groups (Table 2).

\begin{tabular}{|l|c|c|c|}
\hline & VIGILEO GROUP & STANDARD GROUP & p \\
\hline ASA ( $n^{\circ}$ patients) & $\begin{array}{r}\text { I } 1 \mathrm{pt} \\
\text { II } 6 \mathrm{pts} \\
\text { III } 3 \mathrm{pts}\end{array}$ & $\begin{array}{r}\text { I } 1 \mathrm{pt} \\
\text { II } 4 \mathrm{pts} \\
\text { III } 2 \mathrm{pts}\end{array}$ & $>0,05$ \\
\hline Surgical time (average) & $10,5 \mathrm{~h}$ & $10,4 \mathrm{~h}$ & $>0,05$ \\
\hline Age (average) & 61,4 & 67,5 & $>0,05$ \\
\hline BMI (average) & 24,1 & 23,1 & $>0,05$ \\
\hline
\end{tabular}

Table 1: Demographic data, patient's characteristics and surgical time in VIGILEO GROUP and STANDARD GROUP.

ASA: Classification of American Society of Anesthesia, BMI: Body Mass Index $\left(\mathrm{Kg} / \mathrm{m}^{2}\right)$

\begin{tabular}{|l|c|c|c|}
\hline & VIGILEO GROUP & STANDARD GROUP & $\mathbf{p}$ \\
\hline Re-operation ( ${ }^{\circ}$ patients) & 1 & 0 & $>0,05$ \\
\hline $\begin{array}{l}\text { Intra-hospital death } \\
\left(n^{\circ} \text { patients) }\right.\end{array}$ & 0 & 0 & $>0,05$ \\
\hline Hospital LOS (days) & 21,2 & 22,57 & $>0,05$ \\
\hline
\end{tabular}

Table 2: Re-operation and intra-hospital death ( $n^{\circ}$ patients) and hospital Length of Stay (LOS) in VIGILEO GROUP and STANDARD GROUP.

Fluid administration in the intraoperative period, estimated blood losses, urine output are shown in Table 3.

\begin{tabular}{|l|c|c|c|}
\hline & VIGILEO GROUP & STANDARD GROUP & p \\
\hline Volume colloids O.R. $(\mathrm{mL})$ & 625 & 328 & $>0,05$ \\
\hline Volume colloids O.R. (mL/Kg) & 9,79 & 4,57 & $>0,05$ \\
\hline Volume crystalloids O.R. $(\mathrm{mL})$ & 4380 & 4700 & $>0,05$ \\
\hline $\begin{array}{l}\text { Volume crystalloids O.R. } \\
\text { (mL/Kg/h) }\end{array}$ & 6,3 & 6,7 & $>0,05$ \\
\hline Urine output O.R. $(\mathrm{mL})$ & 1909 & 1240 & $>0,05$ \\
\hline Urine output O.R. $(\mathrm{mL} / \mathrm{Kg} / \mathrm{h})$ & 2,78 & 1,72 & $>0,05$ \\
\hline Blood loss (mL) & 375 & 328 & $>0,05$ \\
\hline $\begin{array}{l}\text { Presurgical fluid deficit } \\
\left.\text { (average, } 2 \mathrm{~mL}{ }^{*} \mathrm{Kg}{ }^{*} 12 \mathrm{~h}\right)\end{array}$ & 1641 & 1638 & $>0,05$ \\
\hline $\begin{array}{l}\text { Hemoglobin value at the end } \\
\text { of surgery (g/dL) }\end{array}$ & 10,4 & 9,8 & $>0,05$ \\
\hline
\end{tabular}

Table 3: Intraoperative fluids administration, blood loss, urine output and hemoglobin value. (O.R.: Operating Room).

Dobutamine was used in 6 patients in VIGILEO group while only 1 patient in standard group had a dobutamine infusion while noradrenaline infusion was used in 2 patients of VIGILEO group and none in standard group (Table 4).

\begin{tabular}{|l|c|c|c|}
\hline & VIGILEO GROUP & STANDARD GROUP & $\mathbf{p}$ \\
\hline dobutamine /no dobutamine & $6 / 4$ & $1 / 6$ & $>0,05$ \\
\hline $\begin{array}{l}\text { noradrenaline/ no } \\
\text { noradrenaline }\end{array}$ & $2 / 8$ & $0 / 0$ & $>0,05$ \\
\hline
\end{tabular}

Table 4: Vasoactive drugs infused in VIGILEO GROUP and STANDARD GROUP ( $\mathrm{N}^{\circ}$ of Patients).

\section{Discussion}

Adequate volume intake is a key to maintain an efficient organ perfusion during surgical procedures. The free flaps reconstruction in ENT surgery is a complicated and invasive surgical procedure with fluids depletion from all the compartments (intra-extracellular spaces). An intraoperative liberal fluid administration could cause a vascular barrier dysfunction [2] with a fluids shifting that exacerbates the microvascular damage. Actually the common parameters used to guide perioperative fluid management (heart rate, diuresis, mean 
arterial pressure) have been revealed not efficient to support adequately hemodynamics requests in surgical and ICU patients $[13,14]$. Therefore, the intraoperative fluid loading in high-risk surgical patients could be directed only to fluid responders [15] and, in microvascular clinical settings, a tailored fluids administration is mandatory [16]. Our analysis shows that both groups are comparable in baseline characteristics (patient and surgical related); these data are very important because the influence of preoperative comorbidity in microvascular surgery [17] is related to the perioperative optimization. Recently, several guidelines on perioperative hemodynamic optimization have been published; the French guidelines [18] underline the importance of a fluid management strategy guided by stroke volume variation to reduce postoperative morbidity in patients with high risk of postoperative complications. These concepts are also shown by Della Rocca et al in the recently published rational approach on intraoperative fluid management [19]. During our analysis we haven't found any statistical difference in intraoperative volume fluids administration between patients groups. Several studies have shown that a large intake fluid volume is associated with adverse outcomes and flap complications [20,21], prolonged length of hospital stay [22] or major complications [23]. In the VIGILEO group we have infused more colloids than in STANDARD group; these data derive from "volume boluses" method used to control hemodynamics functional parameters as SVV and CO. In the anesthetic procedures with non-invasive hemodynamic monitoring, we use a volume boluses technique to achieve the optimal hemodynamic target, according to several Goal Directed Therapy (GDT) flowcharts $[18,19,24]$. This is different from standard procedure where we usually prefer a continued fluids infusion regulated only by flow rate. More interesting information's derive from the use of the vasoactive drugs: in VIGILEO group there is a significant use of dobutamine infusion compared to the STANDARD group. The goal in microvascular procedures in major surgery is to achieve an adequate perfusion of the free flaps to provide an optimal perfusion pressure. During microsurgery procedures, a good cardiac output with peripheral vasodilatation and a large pulse pressure [17] is required and, after an adequate intravascular fluids replacement, is mandatory the use of vasoactive drugs. In the STANDARD GROUP the mean arterial pressure, diuresis and lactate values have not support an infusion of dobutamine or noradrenaline, instead in the VIGILEO GROUP the possibility to visualize a numeric value of cardiac output has guided the anesthesiologists to use these drugs. In microvascular free flaps reconstruction the use of vasoactive agents is debated with pro and cons [25] and the only vasoactive agent with a clear adverse outcome is sodium nitroprusside [26]. The possibility to have a cardiac output value with a functional data (SVV) regarding fluids administration, permits, in our opinion, to improve a vascular supply through vasoactive agents. Although the use of nor-epinephrine during Vigileo monitoring could raise some concern about the reliability of cardiac output absolute values, in the only two cases in which it was administered was taken into account only the graphic trending as an hemodynamic guide.

As previous reported, between the two groups there are no difference in the amount of fluids administered: these findings are comparable to previous studies that compared a fluid intraoperative management between similar strategies [24,27]. For this reason, the only difference is about the use of vasoactive drugs in optimizing the microvascular supply in particular dobutamine administration. Dobutamine in a goal directed therapy has shown several benefits [24] to reduce complications rate and, in the free flaps reconstructive surgery, has demonstrated its good role [28] in tissues optimal perfusion. Although it is a common practice to use vital signs, as mean arterial pressure and diuresis, to guide hemodynamic strategy during general anesthesia [29], the simplicity of measuring these parameters is in contrast with their real time usefulness. The physiologic reactions to a cardiac output decrease are tachycardia and hypotension, but normotension is not a synonym of hemodynamic stability [30] and a frequently hypotensive state reflects a large fluids loss [31] with a microvascular remodeling already started. The microvascular tone alteration is the key element to prevent and to avoid a worse free flap outcome. Our retrospective study does not demonstrate that the functional parameters are better to guide the hemodynamic support during free flaps neck and head surgery due to our small sample size, but several studies have yet shown an improvement in perianastomotic microcirculation [32] through a cardiovascular optimization, achieved using functional parameters. Therefore, as described by many authors, right amount of fluid is based on flow and volume macro-hemodynamic parameters [30] tailored on patient's hemodynamic needs. The intraoperative urine output rate, showed in Table 3, is major in VIGILEO GROUP. This data are inconclusive and susceptible to many criticisms but we could speculate that an optimal hemodynamic management with vasoactive drugs performed by functional parameters could improve the renal perfusion, despite of a fluids administration guided by urine output itself and blood pressure values. We are aware that we evaluateda small population (only 17 patients), due to our initial expertise so the data may not have a level of statistical significance that could be considered definitive. Our findings, as previous brief reported [33], are not conclusive and the main limits of this retrospective manuscript are linked to the analysis of only intraoperative period and to the small sample of patients, that did not help to create enough consistency in the data collected. Therefore, several randomized trials including the intra- and postoperative periods are necessary.

\section{References}

1. Patel RS, McCluskey SA, Goldstein DP, Minkovich L, Irish JC, et al. (2010) Clinicopathologic and therapeutic risk factors for perioperative complications and prolonged hospital stay in free flap reconstruction of the head and neck. Head Neck 32: 1345-1353.

2. Chappell D, Jacob M, Hofmann-Kiefer K, Conzen P, Rehm M (2008) A rational approach to perioperative fluid management. Anesthesiology 109: 723740 .

3. Smith I, Kranke P, Murat I, Smith A, O'Sullivan G, et al. (2011) Perioperative fasting in adults and children: guidelines from the European Society of Anaesthesiology. Eur J Anaesthesiol 28: 556-569.

4. Bellomo R (2002) Fluid resuscitation: colloids vs. crystalloids. Blood Purif 20: 239-242.

5. Choi PT, Yip G, Quinonez LG, Cook DJ (1999) Crystalloids vs. colloids in fluid resuscitation: a systematic review. Crit Care Med 27: 200-210.

6. Corcoran T, Rhodes JE, Clarke S, Myles PS, Ho KM (2012) Perioperative fluid management strategies in major surgery: a stratified meta-analysis. Anesth Analg 114: 640-651.

7. Bundgaard-Nielsen M, Secher NH, Kehlet $H$ (2009) 'Liberal' vs. 'restrictive' perioperative fluid therapy--a critical assessment of the evidence. Acta Anaesthesiol Scand 53: 843-851.

8. Ferrier MB, Spuesens EB, Le Cessie S, Baatenburg de Jong RJ (2005) Comorbidity as a major risk factor for mortality and complications in head and neck surgery. Arch Otolaryngol Head Neck Surg 131: 27-32. 
Citation: Bulgheroni R, Bacuzzi A, Guzzetti L, Romano MD, D’Onofrio D, et al., (2014) The Intraoperative Hemodynamic Control through Functional Parameters in Free Flap Reconstruction in Head and Neck Surgery: our Initial Expertise. J Anesth Clin Care 1: 004.

9. de Cássia Braga Ribeiro K, Kowalski LP (2003) APACHE II, POSSUM, and ASA scores and the risk of perioperative complications in patients with oral or oropharyngeal cancer. Arch Otolaryngol Head Neck Surg 129: 739-745.

10. Suh JD, Sercarz JA, Abemayor E, Calcaterra TC, Rawnsley JD, et al. (2004) Analysis of outcome and complications in 400 cases of microvascular head and neck reconstruction. Arch Otolaryngol Head Neck Surg 130: 962-966.

11. Iseli TA, Iseli CE, Golden JB, Jones VL, Boudreaux AM, et al. (2012) Outcomes of intubation in difficult airways due to head and neck pathology. Ear Nose Throat J 91: E1-5.

12. Hagau N1, Longrois $D$ (2009) Anesthesia for free vascularized tissue transfer. See comment in PubMed Commons below Microsurgery 29: 161-167.

13. Michard F, Teboul JL (2002) Predicting fluid responsiveness in ICU patients: a critical analysis of the evidence. Chest 121: 2000-2008.

14. Marik PE, Baram M, Vahid B (2008) Does central venous pressure predict fluid responsiveness? A systematic review of the literature and the tale of seven mares. Chest 134: 172-178.

15. Marik PE, Cavallazzi R, Vasu T, Hirani A (2009) Dynamic changes in arterial waveform derived variables and fluid responsiveness in mechanically ventilated patients: a systematic review of the literature. Crit Care Med 37 2642-2647.

16. Pereira CM, Figueiredo ME, Carvalho R, Catre D, Assunção JP (2012) Anesthesia and surgical microvascular flaps. Rev Bras Anestesiol 62: 563-579.

17. Gardiner MD, Nanchahal J (2010) Strategies to ensure success of microvascular free tissue transfer. J Plast Reconstr Aesthet Surg 63: e665-673.

18. Vallet B, Blanloeil Y, Cholley B, Orliaguet G, Pierre S, et al. (2013) [Guidelines for periopeartivehaemodynamic optimization. Socie'te' franc, aise d'anesthe'sie et de re'animation]. Ann Fr Anesth Reanim 32: 454-462.

19. Della Rocca G, Vetrugno L, Tripi G, Deana C, Barbariol F, et al. (2014) Liberal or restricted fluid administration: are we ready for a proposal of a restricted intraoperative approach? BMC Anesthesiol 14: 62.

20. Haughey BH, Wilson E, Kluwe L, Piccirillo J, Fredrickson J, et al. (2001) Free flap reconstruction of the head and neck: analysis of 241 cases. Otolaryngol Head Neck Surg 125: 10-17.

21. Namdar T, Bartscher T, Stollwerck PL, Mailänder P, Lange T (2010) Complete free flap loss due to extensive hemodilution. Microsurgery 30: 214-217.

22. Patel RS, McCluskey SA, Goldstein DP, Minkovich L, Irish JC, et al. (2010) Clinicopathologic and therapeutic risk factors for perioperative complications and prolonged hospital stay in free flap reconstruction of the head and neck. Head Neck 32: 1345-1353.
23. Franklin J (2002) Morbidity associated with perioperative fluid management in free flap reconstruction of the head and neck. Laryngoscope 112: 765-766.

24. Pestaña D, Espinosa E, Eden A, Nájera D, Collar L et al (2014) Perioperative goal-directed hemodynamic optimization using noninvasive cardiac output monitoring in major abdominal surgery : a prospective,randomized, multicenter, pregmatic trial: POEMAS Study. (PeriOperative goal-directed thErapy in Major Abdominal Surgery). Anesth Analg 119: 579-587.

25. Harris L, Goldstein D, Hofer S, Gilbert R (2012) Impact of vasopressors on outcomes in head and neck free tissue transfer. Microsurgery 32: 15-19.

26. Banic A, Krejci V, Erni D, Wheatley AM, Sigurdsson GH (1999) Effects of sodium nitroprusside and phenylephrine on blood flow in free musculocutaneous flaps during general anesthesia. Anesthesiology 90: 147-155.

27. Mayer J, Boldt J, Mengistu AM, Röhm KD, Suttner S (2010) Goal-directed intraoperative therapy based on autocalibrated arterial pressure waveform analysis reduces hospital stay in high-risk surgical patients: a randomized, controlled trial. Crit Care 14: R18.

28. Scholz A, Pugh S, Fardy M, Shafik M, Hall JE (2009) The effect of dobutamine on blood flow of free tissue transfer flaps during head and neck reconstructive surgery ${ }^{*}$. Anaesthesia 64: 1089-1093.

29. Kastrup M, Markewitz A, Spies C, Carl M, Erb J, et al. (2007) Current practice of hemodynamic monitoring and vasopressor and inotropic therapy in post-operative cardiac surgery patients in Germany: results from a postal survey. Acta Anaesthesiol Scand 51: 347-358.

30. Strunden MS, Heckel K, Goetz AE, Reuter DA (2011) Perioperative fluid and volume management: physiological basis, tools and strategies. Ann Intensive Care 1: 2 .

31. Webb AR (2001) Recognizing hypovolaemia. Minerva Anestesiol 67: 185189.

32. Kimberger O, Arnberger M, Brandt S, Plock J, Sigurdsson GH, et al. (2009) Goal-directed colloid administration improves the microcirculation of healthy and perianastomotic colon. Anesthesiology 110: 496-504.

33. Abdel-Galil K, Craske D, McCaul J (2010) Optimisation of intraoperative haemodynamics: early experience of its use in major head and neck surgery. $\mathrm{Br}$ J Oral Maxillofac Surg 48: 189-191. 